\title{
Omega-3 gantz-azidoen propietate onuragarriak zenbait egoera klinikotan
}

\section{(Beneficial properties of omega-3 fatty acids in human disease)}

\author{
Maitane Serrano*, Irantzu Rico-Barrio, Leire Lekunberri, \\ Almudena Ramos-Uriarte, Nagore Puente, Izaskun Elezgarai, Pedro Grandes
}

Neurozientziak Saila. Medikuntza eta Erizaintza Fakultatea (UPV/EHU, Leioa, Bizkaia) Achucarro Basque Center for Neuroscience, UPV/EHUko Zientzia Parkea

(UPV/EHU, Leioa, Bizkaia)

\begin{abstract}
LABURPENA: Kate luzeko omega-3 mantenugaiak, azido $\alpha$-linolenikoa (ALA), azido eikosapentaenoikoa (EPA) eta azido dokosahexaenoikoa (DHA), dietaren bitartez bereganatzen diren gantz-azido (GA) poliasegabeak dira. Propietate antioxidatzaileak barne hartzen dituzten hiru osagai horien elikagai-iturri nagusia arrain koipetsua (izokina, antxoa, hegalaburra...) eta horretatik eratorritako arrain-olioa dira batez ere. Omega-3 GA osagarriaz aberastutako dietak aldaketa molekular zein funtzional mesedegarriak eragiten ditu garunaren garapen prozesuan, zenbait garun lesioren berreskurapenean parte hartzen. Gehigarri horrek mintz zelularraren fluidotasuna areagotzen du, eta metabolismoaren erregulazioan parte hartzen du, seinaleztapen molekulen askapena sustatuz eta gene espresioan eraginez. Bi ekintza horien bidez seinaleztapen bideak aktibatzen dira, eta ondorioz garun plastikotasuna eta transmisio sinaptikoa suspertu. Areago, omega-3 GAk zeluletan oro har, eta neuronetan bereziki, oxidazio-estresak eta hanturak eragindako kalteak murriztu ditzake. Horregatik guztiagatik, omega-3 osagarria hainbat patologietan prebentzioan edo tratamenduan erabili da. Berrikuspen honek laburbiltzen ditu kate luzeko omega-3 GAetan aberastutako tratamenduak bihotz hodietako gaixotasunetan, minbizian, neuroendekapenezko gaixotasunetan (Alzheimer eta Parkinson), alkoholismoan eta gainpisuan, oinarrizko ikerkuntzan eta ikerketa klinikoan frogatu eta egiaztatu diren aurrerapen terapeutiko berriak; eta etorkizunera begira beste hainbat gaixotasuni aurrea hartzeko edo haiek tratatzeko potentzialtasun handiko eta albo ondoriorik gabeko osagarri ez-inbaditzaile aproposa izan daitekeela iradokitzen du.
\end{abstract}

HITZ GAKOAK: Omega-3; gantz-azidoak; dieta; bihotz-hodietako gaixotasunak; garun gaixotasunak; metabolismo arazoak; terapia.

ABSTRACT: Omega-3 fatty acids (FA) are essential long-chain polyunsaturated FA, amongst others, $\alpha$-linolenic acid $(A L A)$, eicosapentaenoic acid (EPA) and docosahexaenoic acid (DHA). The main food source of omega-3 is the oily fish which is found in salmon, anchovy or tuna. A diet enriched with omega-3 is known to favour healthy states by promoting molecular and functional changes during brain damage recovery, membranes fluidity, energy metabolism regulation, release of signalling molecules or gene expression. Likewise, the activation of signalling pathways by omega-3 improves neural transmission and plasticity and decreases oxidative stress and inflammation in cells, particularly in neurons. Therefore, omega-3 supplements have been used to prevent or treat many human disorders. This review is intended to provide the stateof-the art of omega-3 as a natural component with beneficial therapeutic properties in cardiovascular and neurodegenerative diseases (Alzheimer and Parkinson), cancer, alcoholism and overweight. Lastly, some insights into the potential benefits of omega-3 supplementation to dodge or treat some other diseases in the future are also considered.

KEYWORDS: Omega-3; fatty acids; diet; cardiovascular disease; brain disease; metabolism disorders; therapy.

\footnotetext{
* Harremanetan jartzeko / Corresponding author: Maitane Serrano. Neurozientziak Saila. Medikuntza eta Erizaintza Fakultatea (UPV/EHU, Leioa, Bizkaia). - maitane.serrano@ehu.eus - https://orcid.org/0000-0002-8296-9231.

Nola aipatu / How to cite: Serrano, Maitane; Rico-Barrio, Irantzu; Lekunberri, Leire; Ramos-Uriarte, Almudena; Puente, Nagore; Elezgarai, Izaskun; Grandes, Pedro (2020). «Omega-3 gantz-azidoen propietate onuragarriak zenbait egoera klinikotan»; Ekaia, 38, 2020, 73-95. (https://doi.org/10.1387/ekaia.21840).
}

Jasoa: 24 ekaina, 2020; Onartua: 08 abuztua, 2020.

ISSN 0214-9001 - elSSN 2444-3255 / (c) 2020 UPV/EHU

Obra hau Creative Commons Atribución 4.0 Internacional-en

lizentziapean dago 
Maitane Serrano, Irantzu Rico-Barrio, Leire Lekunberri, Almudena Ramos-Uriarte, Nagore Puente, Izaskun Elezgarai, Pedro Grandes

\section{OMEGA-3 GANTZ-AZIDOAK}

Mantenugaiak elikagaietan dauden substantzia kimikoak dira eta zelulen funtzio energetikoan, egituratzailean eta erregulatzailean parte hartzen dute [1]. Mantenugaien artean lipidoak ditugu, gantz-azidoz (GA) osatutako substantzia organikoak. GAk egitura hidrokarbonatuko kateak dira. Katearen hasierako muturrean karboxilo talde bat aurkezten dute, eta katearen amaieran, berriz, metilo talde bat. Kate horietan lotura bikoitzak gerta daitezke, eta GA asegabeak sortu. Lotura bikoitz horien kokapenaren arabera, GA ezberdinak sortzen dira, eta, horiek izendatzeko, metilo taldetik hasita lehenengo lotura bikoitzaren kokapena erabiltzen da. Zehazki, lotura bikoitza metilo taldetik hasita 3. eta 4. karbonoen artean daukaten gantzei omega-3 deritze [1-4]; 6. eta 7. karbonoen artean daukaten gantzei omega-6, eta 9. eta 10. karbonoen artean daukatenei, berriz, omega-9 [3]. Omega-3 GA garrantzitsuenak kate luzekoak dira, 18 karbono atomo edo gehiago dituzten kateak, hain zuzen ere. Horien artean, azido $\alpha$-linolenikoa (ALA, 18:3), azido eikosapentaenoikoa (EPA, 20:5) eta azido dokosahexaenoikoa (DHA, 22:6) azpimarratzekoak dira [2-6] (1. irudia).

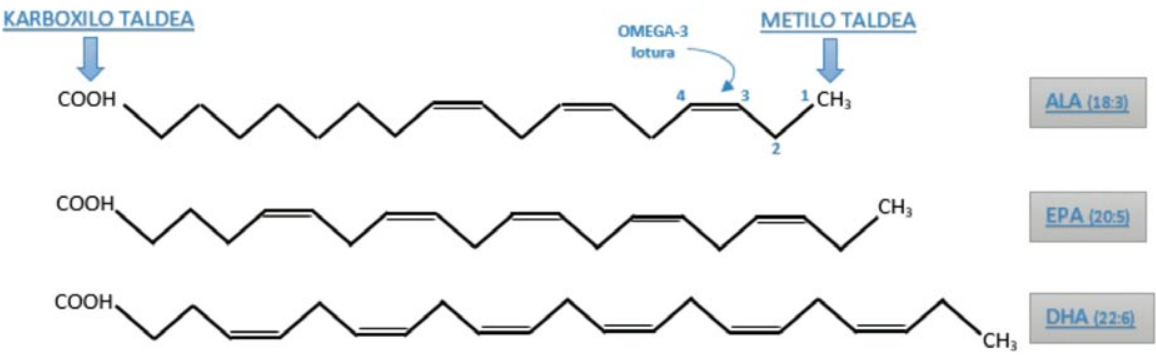

1. irudia. Omega-3 garrantzitsuenen egitura kimikoa.

\subsection{Omega-3 gantz-azidoen funtzioak}

Omega-3 GAen funtzio nagusiak energia-iturri izatea, seinaleztapen molekulak sortzea (eikosanoideak, dokosanoideak) eta zelula-mintzen osagai izatea dira [1, 5-8]. DHA, erretinan eta garunean kantitate handitan ageri da $[1,8,9]$. Izan ere, sinapsien eta neuronen sorkuntzarako eta azken horien migraziorako ezinbestekoa da $[1,10,11]$. EPAk, berriz, efektu hipotriglizeridemikoa, hipokolesterolemikoa, hodi-zabaltzailea eta antitronbotikoa aurkezten ditu [1, 8]. Horrez gain, EPAtik eta DHAtik sortzen diren seinaleztapen molekulek hantura-kontrako efektua daukate $[1,4,5,9,12]$, eta nahiz eta gaur-gaurkoz mekanismoa ezezaguna izan, osagai horiek apoptosia inhibitzen dute; hala, zelulen biziraupena bermatuz eta eginkizun babeslea gauzatuz; nerbio-sisteman, besteak beste [1]. 
Bestalde, omega-3 GAk mintz zelularren osagai dira, eta horien fluidotasunean eragina dute. Mintzeko zelulak kitzikagarriak baldin badira, omega-3 GAek paper garrantzitsua jokatzen dute seinale-transdukzioan, mintzari lotuta dauden hartzaile, ioi-kanal eta entzimen aktibitatea egokia izaten ahalbidetuz $[1,5,6,9]$. Funtzio horiek izateaz gain, omega-3 GAek kontrol genikoan ere parte hartzen dute peroxisoma proliferatzaileen bidez aktibatutako hartzaileei (PPAR) lotuz. Izan ere, dietaren bidez jasotako omega-3-ek lipidoen sintesian parte hartzen duten entzimak kodifikatzen dituzten geneen transdukzioa inhibitzen dute $[1,13]$. $\beta$-oxidazioan parte hartzen duten entzimak kodifikatzen dituzten geneen kasuan, ordea, transdukzioa suspertzen dute $[1,13,14]$.

\subsection{Omega-3 gantz-azidoak dietan}

Ugaztunak elongazio eta asegabetasun prozesuen bidez GAk eraldatzeko gai dira. Hala ere, ugaztunek, omega-9-tik karboxilo muturreraino sor ditzakete soilik lotura asegabe horiek. Horren ondorioz, ALA nahitaezko GA da; hau da, dietaren bidez bereganatu behar da [1,2,11]. ALAtik abiatuta EPA eta DHA sor daitezke. Aitzitik, lortzen diren kantitateak oso txikiak dira; are gehiago, EPA ALAtik abiatuta sortzen bada, bitartekari gisa jokatuko du, eta, hortaz, ez ditu bere jatorrizko funtzioak beteko. Horrexegatik, ez ALA bakarrik, baizik eta gainerako omega-3 garrantzitsuenak ere dietaren bidez bereganatu behar dira $[1,4,12]$.

Dietaren bidez omega-3 kantitate egokiak hartu behar izateaz gain, omega-6/omega-3 ratioa ere kontuan hartu behar da [1,5]. Bi omega mota horietatik abiatuta, gorputzeko homeostasia mantentzeko ezinbestekoak diren produktu eratorriak sortzen dira, eta, jomuga horretarako, entzima berdinak erabiltzen dira; $\delta-5$ eta $\delta-6$ desaturasak eta hainbat elongasa, besteak beste. $\delta-6$ desaturasa entzimak afinitate handiagoa dauka omega-3-rekiko omega-6-ekiko baino. Horren ondorioz, omega-6/omega-3 ratioa 4:1-5:1 tartekoa izatea gomendatzen da, betiere 10:1-eko proportzioa gainditu gabe; eratorrien sorkuntza desorekatua izan ez dadin $[1,5,8]$. Ildo horretatik, jakina da mendebaldeko dieta patroiak nabarmen aldatuz joan direla. Izan ere, lipido kontsumoari dagokionez, omega-6 GAen ahorakina handitu da, eta omega-3-ena, ordea, nabarmen gutxitu [5], ratioa 15:1-20:1 tartekoa izanik [2].

Dieta desorekatuek, nahitaezko GA kantitate nahikoa ez duten dietek edo omega-6/omega-3 ratioa aproposa ez duten dieta horiek ondorio kaltegarriak eragin ditzakete gure osasunean [1]. Dieta desorekatuetan, omega3 -ek ez dituzte beren funtzioak egoki betetzen; beraz, zenbait gaixotasunetan eragin dezaketen prebentzio eta tratamendu gaitasuna galtzen da, hala nola bihotz-hodietako gaixotasunetan [5, 6], endekapenezko gaixotasune$\tan [5]$ eta 2 motako diabetesean $[1,6]$. 


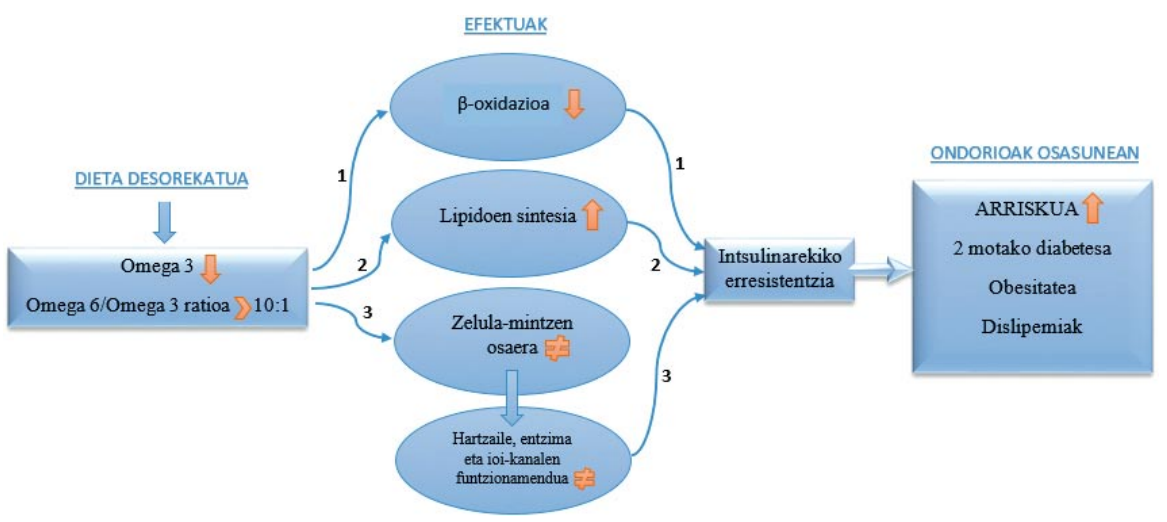

2. irudia. Omega-3 GAetan eskasa den dietaren edo omega-6/omega-3 ratio desegokia aurkezten duen dietaren ondorioak osasunean.

Laburbilduz, omega-3 GAk gorputzeko homeostasia mantentzeko beharrezkoak diren osagaiak dira. Hala ere, gaur egun jarraitzen ditugun dietek nekez betetzen dituzte omega-3-en inguruko beharrak, eta 2 motako diabetesa, obesitatea edo dislipemiak pairatzeko arriskua nabarmenagoa da (2. irudia). Berrikusketa honen helburua da omega-3 GAek hainbat gaixotasunetan terapia gisa erabilita eduki ditzaketen efektu onuragarriak aztertzea. Zehazki, berrikusketa honek biltzen ditu bihotz-hodietako gaixotasunetan, minbizian, neuroendekapenezko gaixotasunetan, alkoholismoan eta gainpisuan (oinarrizko ikerkuntzan zein ikerketa klinikoan) omega-3 GA gehigarriek dakartzaten efektu mesedegarriak edo onurak.

\section{BIHOTZ-HODIETAKO GAIXOTASUNAK}

Bihotz-hodietako gaixotasunak bihotzeko eta odol-hodietako arazoei deritze, eta mundu osoko heriotzen lehenengo kausa dira. 2015. urtean 17,7 milioi pertsona bihotz-hodietako eritasunen ondorioz hil ziren; erregistratutako heriotza guztien \% 31, alegia [15]. Euskal Autonomia Erkidegoak argitaratutako datuen arabera, nahiz eta gaixotasun multzo horren ondoriozko heriotza kopurua urtez urte jaitsiz joan den, oraindik ere lehenengo heriotza kausa dira. Hain zuzen ere, 2014. urtean bihotz-hodietako gaixotasunak heriotza guztien \% 27,5 izan ziren [16].

Bihotz-hodietako gaixotasunak edukitzeko arrisku-faktore garrantzitsuenak hipertentsio arteriala, diabetesa eta hiperlipidemia dira, baita tabakoa erretzea, dieta desorekatuak, gainpisua, sedentarismoa eta alkohol kontsumoa ere $[15,16]$. Nahiz eta bihotz-hodietako gaixotasunen prebalentzia urtez urte jaitsiz joan den, arrisku faktoreen prebalentzia urtez urte gora 
joan da [16]. Hortaz, bihotz-hodietako gaixotasunak dituzten pertsonen artean, berebiziko garrantzia dauka detekzio eta tratamendu goiztiarra ezartzea, heriotza probabilitatea eta eragin kaltegarriak murrizteko [15].

\subsection{Bihotz-hodietako gaixotasunak eta omega-3 gantz-azidoen onurak oinarrizko ikerkuntzan}

1990eko hamarkadarako, bihotz-hodietako gaixotasunen eta omega-3 GAren arteko erlazioaren inguruko lehenengo ikerketak egiten hasi ziren animalietan. Hain zuzen ere, 60 Hooded-Wistar motako arratoi arrak hiru taldetan banatu ziren ezarritako dietaren arabera - gantz baxuko kontrol dieta, gantz asetan aberastutako dieta eta arrain olioarekin aberastutako dieta - eta talde bakoitzeko kumaldi erdiari, 15 minutuko iskemia prozesua bihotzean eragin zitzaien. Emaitzek agerian jarri zuten arrain olioarekin aberastutako dietak onuragarriak izan zirela eta arritmien kontrako efektuak lortu zituztela. Izan ere, dieta mota hori jasotako arratoiek iskemia osteko perfusioan ez zuten takikardiarik ezta bentrikuluko fibrilaziorik agertu. Areago, animalia horietan arritmiaren bat sortzekotan, bihotza era espontaneoan erritmo sinusalera bueltatzen zen [17]. Horren ostean, antzeko ikerketak zertu dira, non, 30 minutuko iskemia prozesuak eraginez Hooded-Wistar motako arratoiek jasotako olioarekin aberastutako dietaren emaitzek ildo bereko onurak adierazi dituzten. Maila altuko EPA eta DHA dituzten dietek arritmien kontrako propietateak aurkezten dituzte, eta iskemia osteko berreskuratzea hobea dela egiaztatu da. Orobat aipatzekoa da bihotzekoen aurrean aurkezten duten funtzio babesle nabarmena $[18,19]$.

Horrez gain, omega-3-an aberastutako dietak onura nabarmenak eragiten dizkie 45 minutuko garun-iskemia jasandako 21 asteko C57BL/6J saguei, gai zuriaren osotasuna, angiogenesi eta neurogenesi prozesuak areagotuz [20]. Are gehiago, omega-3-ko dietak, garun-iskemiak kaltetutako garuneko azalera eta larritasuna apaltzeaz gain, iskemiaren ondorioz agertzen diren arazo motorrak hobetzen ditu [21], bai eta garun-iskemiaren ondorioz ager daitezkeen oroimen eta ikasketa arazoak ere [22, 23].

\subsection{Bihotz-hodietako gaixotasunak eta omega-3 gantz-azidoen onurak ikerketa klinikoan}

Bihotz-hodietako eritasunekin eta omega-3 GAen onurekin zerikusia duten saiakuntza klinikoak ere aurrera eraman dira azken hamarkadetan. Hain zuzen ere, miokardioko bihotzekoa pairatutako 11.324 pazienteri egunero $1 \mathrm{~g}$ omega-3 gehigarri emateak eta bihotzeko gutxiegitasun kronikoa pairatzen zuten pazienteei eguneroko dietan omega-3 gehigarria emateak heriotza-tasa orokorra eta bihotz-hodietako gaixotasunen ondoriozko heriotza-tasa jaitsarazi zituen $[24,25]$. Horretaz aparte, gaixoek jasotako omega- 
Maitane Serrano, Irantzu Rico-Barrio, Leire Lekunberri, Almudena Ramos-Uriarte, Nagore Puente, Izaskun Elezgarai, Pedro Grandes

3-an aberastutako dietak bihotz-hodietako arazoek eragindako ospitalizazio-maila murritzarazi zuen [25].

Horren harira, hiperkolesterolemia pairatzen zuten 18.624 gaixori 5 urtez emandako estatina bidezko tratamenduan ere (soilik edo EPArekin batera), gehigarriaren onurak berretsi ziren. Izan ere, buruko isuria jasandako pazienteen artean, \% 20ko errepikapenen murriztapena behatu zen, EPA dieta gehigarriaren potentzialtasuna iradokiz [26]. Ildo berean, dilatatutako kardiomiopatia ez iskemikoa pairatzen zuten 133 pertsonari urtebetez $2 \mathrm{~g}$ omega-3 gehigarri jasotzearen ondoriozko ezkerreko bentrikuluko funtzio sistolikoa eta bolumen gaitasuna hobeak deskribatu ziren, eta bihotzeko gutxiegitasunaren ondoriozko ospitalizazioak gutxitu [27]. Hala ere, beste zenbait ikerketatan omega-3 GAek ez dituzte onurarik erakutsi, eta osagai horien eraginkortasuna zalantzan jarri dute [28].

\section{MINBIZIA}

Minbizia gorputzeko zelulak kontrolik gabe zatitu eta alboko ehunetara barreiatzen direnean sortzen diren gaixotasunei deritze hala. Azken prozesuari metastasia deritzo, eta minbiziaren ondoriozko heriotzen kausarik ohikoena da. Minbizia, mundu mailan, bigarren heriotza-kausa da. Izan ere, 2018. urtean 9,6 milioi hildako eragin zituen, hau da, 6 heriotzetatik 1 minbiziaren ondoriozkoa izan zen [29]. Euskal Autonomia Erkidegoan azken 5 urteetan 41.031 pazienteri minbizia diagnostikatu zaie, zeinetatik $\% 53,18$ emakumezkoak izan diren. 2019. urteko minbizi ohikoenak bularrekoa, kolonekoa eta prostatakoa izan dira. Hala ere, sexuen arteko bereizketa egitea garrantzitsua da (1. taula) [30].

1. taula. 2019. urteko minbizi moten prebalentzia eta heriotza kausa ohikoenak Euskal Autonomia Erkidegoan, sexuaren araberako bereizketa eginda.

\begin{tabular}{c|cc}
\hline & Ohikoenak & Heriotza kausa \\
\hline \multirow{2}{*}{ Gizon } & Prostatakoa & Birikakoa \\
& Kolonekoa & Kolonekoa \\
\hline \multirow{2}{*}{ Emakume } & Bularrekoa & Bularrekoa \\
& Kolonekoa & Kolonekoa \\
\hline
\end{tabular}

\subsection{Minbizia eta omega-3 gantz-azidoen onurak oinarrizko ikerkuntzan}

Minbizian, zelulek ezohiko ezaugarriak bereganatzen dituzte. Hori dela eta, gaixotasun horien inguruan ikertzeko, animaliak erabiltzeaz gain, zelula-hazkuntzak ere erabiltzen dira maiz. 
Minbizi moten inguruan ikertzen da, eta aipatzekoa da emakumeetan oso ohikoa den bularreko minbiziaren inguruan egindako hainbat ikerketatan jasotako datuak. Bularreko minbizian zelula-lerro erabilienak MDAMB-231 eta MCF-7 dira. Zelula horiek DHArekin tratatzean, horien bideragarritasuna nahiz entzima onkogenikoen aktibitatearen gutxipena behatu da [31]. Areago, E bitaminarekin batera ere tumoreen oldarkortasuna murrizten da [32]. Shenglong Zhuk eta aren kideek omega-3-a rapamizinarekin batera bularreko minbizian tratamendu gisa eraginkorra izan zitekeen aztertu zuten zeluletan zein sagu immunogutxituetan. Ikerketa horretan, omega-3-ak rapamizinak eragiten dituen bigarren mailako efektuak, hala nola hipertriglizeridemia eta hiperkolesterolemia, era esanguratsuan murrizten zituen [33]. Horrez gain, kirurgia bidez bularreko tumore primarioa kentzean omega-3 GAtan aberastutako dieta jasotako saguetan biriketako metastasia gertatzeko probabilitatea nabarmen gutxitzen zen [34].

Prostatako xangrea da gizonezkoen artean minbizirik ohikoena. Prostatako minbizian, omega-3 GAek zelula-lerro ezberdinen bideragarritasuna gutxitzen dute [35]. Hori gutxi ez, eta saguetan egindako hainbat ikerketak omega-3-ek tumoreen hazkuntza geldotzen dutela frogatu dute [36, 37].

\subsection{Minbizia eta omega-3 gantz-azidoen onurak ikerketa klinikoan}

Animalia eta zelula-lerroetan egindako bularreko minbiziaren inguruko ikerketekin bat datozen emaitzak lortu dira saiakuntza klinikoetan. Bularreko minbizian, kimioterapiarekin eta mastektomiarekin batera omega-3 gehigarria ematen da. Horrela, emakumeen biziraupena handitzen da. Horrez gain, zelula-proliferazioaren eta angiogenesiaren isla diren proteinen espresio-maila murrizten da [38]. Ildo bereko beste ikerketa batean, bularreko minbizia zuten emakumeetan DHA gehigarriek azido epoxidokosapentaenoiko (EDP) mailak igo zituzten. EDPa tumore hazkuntzaren kontra eragiten duen sustantzia da; beraz, DHA gehigarrien eragin positiboa agerian jarri zen. Bularreko minbiziarekin erlazionatutako gene-mutazioak dituzten pazienteetan gehigarriek eragin berdina erakutsi dute. Eragin onuragarri horrek berebiziko garrantzia hartzen du; izan ere, paziente horietan tratamenduak urriagoak dira, eta horien eraginkortasuna txikiagoa [39].

Koloneko minbizia emakume nahiz gizonezkoetan prebalentzia altua aurkezten duen gaixotasuna da. Omega-3-an aberastutako dietak koloneko minbiziaren ondoriozko heriotza-arriskua jaisten du [40, 41], minbizi errezidiba jaitsi eta minbizia gainditu duten pazienteen biziraupena handitzen du [41].

Minbiziaren ondorioak askotarikoak dira, eta horien artean pisu-galera oso ohikoa da. Izan ere, ondorio arrunta da; minbizi mota batzuetan bereziki, area eta birika minbizian esaterako [42]. Ikerketa anitz egin dira omega-3 gehigarriek minbiziaren ondoriozko pisu-galeran eduki ditzaketen 
Maitane Serrano, Irantzu Rico-Barrio, Leire Lekunberri, Almudena Ramos-Uriarte, Nagore Puente, Izaskun Elezgarai, Pedro Grandes

efektuak aztertzeko, non pazienteen pisua eta gorputz-konposizioa mantentzeko [43-45] eta pisu-galera nabarmena eduki duten pazienteen pisua leheneratzeko tratamendu aproposa direla frogatu den [46].

\section{NEUROENDEKAPENEZKO GAIXOTASUNAK}

Neuroendekapenezko gaixotasunak sendaezinak eta ahulgarriak izateaz gain, neuronen etengabeko endekapena edota heriotza eragiten duten gaitzak dira. Ondorioz, gaitz hauek arazoak sortzen dituzte bai mugimenduan (ataxia) baita garun funtzionamenduan (dementzia) ere [47].

Neuroendekapenezko gaixotasunen artean, Alzheimer eta Parkinson gaixotasunak azpimarratu behar dira, eritasun horien prebalentzia altua eta larritasuna direla eta. Endekapenezko gaixotasunak betidanik adinarekin lotuta egon dira. Beraz, populazioaren etengabeko zahartzearekin batera gaixotasun horien prebalentzia igoz joan da. Euskal Autonomia Erkidegoaren datuen arabera, 2018. urtean 40.000 pertsonak narriadura kognitiboa pairatu zuten, zeinetatik 30.000ri Alzheimerra diagnostikatu zitzaien [48].

\subsection{Neuroendekapenezko gaixotasunak eta omega-3 gantz-azidoen onurak oinarrizko ikerkuntzan}

Alzheimer gaixotasunean, Tg2576 saguak izaten dira erabilienak oinarrizko ikerkuntzan. Tg2576 saguetan omega-3, eta bereziki DHA, ezinbestekoa da plastikotasun sinaptikoari lotutako arazo kognitiboak ekiditeko, oxidazio-estresa murrizteko eta dendriten egoera hobetzeko [49]. Horrez gain, gehigarri horrek amiloide aitzindaria den proteinaren sorkuntza bideak [50], plaka amiloideen pilaketa $[50,51]$ eta metaketa horri lotutako odoljarioak [51] murrizten ditu. Izan ere, DHA bidezko tratamenduak hipokanpoko zelula-proliferazioa eta horri lotutako oroimen espaziala hobetzen ditu [52].

Parkinson gaixotasunean, omega-3 gehigarrien bidez gliaren aktibazioarekin eta oxidazioarekin lotutako entzima maila murrizten dira, inflamazioaren eta oxidazioaren kontrako gaitasunak agerian jarriz [53]. Horrez gain, bai zelula-hazkuntzetan bai garun-xafletan egindako esperimentuetan omega-3-ek gorputz ildaskatuko zelula dopaminergikoen heriotza gutxitzen edo leheneratzen dutela frogatu da [54].

\subsection{Neuroendekapenezko gaixotasunak eta omega-3 gantz-azidoen onurak ikerketa klinikoan}

Omega-3 gehigarriekin tratatutako Alzheimerra pairatzen zuten 204 pazientek funtzio kognitiboa denboran zehar mantentzea lortu dute $[55,56]$. 
Are gehiago, Alzheimer gaixotasunaren hasieran gehigarrien erabilerak pazienteen aldizkako oroimena hobetzen du [57]. Hala ere, sintoma neuropsikiatrikoetan ez da ezberdintasun esanguratsurik topatu omega-3 edo plazeboa jasotako taldeen artean [58].

Parkinson gaixotasunean, pertsonekin egindako saiakuntzak urriagoak dira, gaixo horiekin dieta zehatzak aurrera eramateko zailtasunak direla eta. Omega-3 eta $\mathrm{E}$ bitamina gehigarria jasotako 30 parkinsondun pazientetan UPDRSko (Parkinson egoera ebaluatzeko eskala) eta serumeko intsulina balioak kontrol pazienteetan baino txikiagoak zirela ikusi zen [59]. Gene espresioari dagokionez, gehigarrien bidez nekrosi tumoralaren $\alpha$ faktore (TNF- $\alpha$ ) izeneko inflamazio-zitokinaren eta dentsitate baxuko lipoproteinen (LDL) hartzailearen gene espresioa jaisten da [60]. Parkinson gaixoetan agertzen den intsulinarekiko erresistentzia eta seinalizazio desegokia neuroendekapenaren eta inflamazioaren eragile diren aktibitate estrazelularrekin erlazionatuta egon daitekeela ikusi da; bi horiek Parkinson gaixotasunaren sustatzaile nagusiak izanik [61]. Beraz, Parkinsonean omega-3 eta E bitamina gehigarriak, gluzemiaren kontrolean eta inflamazio-markatzaileetan duten eragina kontuan hartuz, sintoma neurologikoak kontrolatzeko aukera ona izan daitezkeela ondoriozta daiteke.

\section{ALKOHOLA}

Alkohola mundu mailan gehien kontsumitzen den substantzia psikoaktiboa da. Munduko Osasun Erakundeak argitaratutako datuen arabera, 2016an Europan 15 urtetik gorako populazioaren \% 59,9 alkohol-kontsumitzaile ohikoa zen. Gainera, alkoholak urtero 3 milioi hildako eragiten ditu; mundu osoko heriotzen \% 5,3 hain zuzen ere [62].

Euskal Autonomia Erkidegoan 2017. urtean, 15 urtetik gorako populazioaren $\% 81,2 \mathrm{k}$ alkohola kontsumitu du noizbait, eta \% 66,3rentzat ohikoa da alkohola astebururo kontsumitzea. Gainera, alkohol kontsumoa 16,8 urterekin hasten da batez beste, hau da, nerabezaroan [63]. Hazkuntza garaian alkohol kontsumoak ondorio larriak ditu, maila fisikoan, emozionalean eta portaeran. Garai horretan garunaren garapena bukatu gabe dago; hortaz, epe luzera patologiaren bat garatzeko, kalte neurologikoen ondorioz ikasketa arazoak edukitzeko eta helduaroan alkoholarekiko mendekotasuna garatzeko probabilitatea zeharo handitzen da [64, 65].

\subsection{Alkohola eta omega-3 gantz-azidoen onurak oinarrizko ikerkuntzan}

Alkoholaren inguruko ikerketa gehienak jaio aurreko alkoholarekiko esposizioak sortzen dituen kalteak aztertzera eta horien kontrako tratamen- 
Maitane Serrano, Irantzu Rico-Barrio, Leire Lekunberri, Almudena Ramos-Uriarte, Nagore Puente, Izaskun Elezgarai, Pedro Grandes

dua bilatzera bideratzen dira. Egoera horren aurrean, omega-3-ek alkoholak aldarazitako glutatioi mailak eta sagu arretan hipokanpoko plastikotasun sinaptikoaren kalteak berreskuratzen dituzte [66, 67]. Horrez gain, alkohol kontsumoaren ondorioz saguei komunikatzeko gaitasuna ematen dieten bokalizazio ultrasonikoen frekuentzian gertatzen den galera eta portaera sozialaren murrizketa berreskuratzen ditu DHAk [68]. Gainera, omega-3-ek alkoholarekiko esposizioak barrabiletan eta espermatozoideetan eragindako kalteak murrizten dituzte. Hain zuzen ere, testosterona sorkuntzan parte hartzen duen genearen espresioa maila arruntetara leheneratzen dute, eta espermatozoide kalitatea hobetzen dutela egiaztatu da [69]. Areago, alkoholak barrabiletan sortutako aldaketa histopatologikoak eta morfometrikoak arrain omega-3-en bidez hobetzen dira [70].

Gibeleko gutxiegitasun alkoholikoari dagokionez, omega-3 GAek alkoholak gibelean sortzen dituen kalteak murrizten dituzte. Alde batetik, GAek TNF- $\alpha$ eta IL-1 $\beta$ inflamazio-zitokinen mailak jaitsarazten dituzte. Bestalde, adipozitoetan gertatzen den lipolisia gutxitzen dute. Horrela, omega-3-ek gibelean pilatzen den gantz kantitatea eta inflamazioa murrizten dituzte [71].

In vivo eta in vitro egindako ikerketetan, DHAk neuronen inflamazioarekin erlazionatutako proteinetan eta oxidazio-estresean gertatzen diren asaldurak deuseztatzen ditu $[72,73]$. Beraz, DHA alkoholak eragindako neuronen inflamazioaren eta endekapenaren kontrako erreminta aproposa izan daitekeela iradoki da.

\section{GAINPISUA}

1975. urtetik 2016. urtera arte obesitatearen prebalentzia hirukoiztu egin da munduan [74]. Gainpisua edukitzeko arrazoi nagusia elikadura eta jarduera fisikoko ohiturak aldatzea da. Gaur egun, ingurumenaren nahiz gizartearen bilakaera oso handia da, eta elikadurako nahiz ariketa fisikoko ohiturak mantendu eta errazteko ahaleginik ez da egiten.

Argitaratutako datuen arabera, 2017. urtean Euskal Autonomia Erkidegoan 18 urtetik gorako populazioaren $\% 35,9 \mathrm{k}$ gainpisua zuen, eta $\% 13,8 \mathrm{k}$, berriz, obesitatea; prebalentzia altuagoa gizonezkoetan izanik. 2 eta 17 urte bitarteko populazioan, gainpisua \% 13,6koa da, eta obesitatea \% 11,1koa batez beste. Kasu horretan, gainpisu prebalentzia altuagoa zen nesketan (\% 14,6); obesitate prebalentzia, ordea, mutiletan (\% 12,8) [75].

Gainpisuaren arazo nagusietakoa gantza abdomenean pilatzea da, hainbat gaixotasun garatzeko arrisku-faktorea baita; bihotz-hodietako gaixotasunak, diabetesa, lokomozio-aparatuko arazoak eta minbizia besteak beste $[74,76]$. 


\subsection{Gainpisuaren ondorioak eta omega-3 gantz-azidoen onurak oinarrizko ikerkuntzan}

Omega-3-ek, eta bereziki EPAk, abdomenean pilatzen den gantz kantitatea jaisten dute [76-78], eta pisu irabaztea moteltzen laguntzen dute [78, 79]. Horrez gain, EPA gehigarriak gantz pilaketa bultzatzen duen PPAR $\gamma$ genearen espresioa jaitsarazten du. Baita dieta hiperkalorikoaren ondoriozko $\mathrm{TNF} \alpha$-ren eta beste inflamazio-zitokinen igoera ere [77, 79, 80]. Horrez gain, glukosaren eta GAen metabolismoan parte hartzen duen adiponektina izeneko hormonaren sorrera bultzatzen du [77, 79, 81].

Horren harira, arrain olioak gainpisua daukaten karraskarietan zenbait parametro metaboliko hobetzen ditu, hala nola odoleko triglizerido [78, 79], kolesterol eta glukosa mailak [78]. Horrez gain, intsulina mailak jaisten ditu, eta hala intsulinarekiko sentikortasuna hobetu $[79,81]$ eta proteinetan nahiz lipidoetan gertatzen den kalte oxidatiboa murriztu [76]. Gainera, gehigarria jaso duten animalietan adipozitoen azalera eta diametroa kontroletan baino txikiagoa dela frogatu da [78]. Garunari dagokionez, omega-3 GAek obesitateak gorputz ildaskatuko arnasa-kate mitokondrialean eragiten dituen kalteak berreskuratzen dituzte [80].

\subsection{Gainpisuaren ondorioak eta omega-3 gantz-azidoen onurak ikerketa klinikoan}

Animalietan egindako ikerketetan lortutako hainbat emaitza umeekin egindako ikerketetan ere frogatu dira. Obesitatea eta intsulinarekiko erresistentzia zeuzkaten umeekin egindako entseguetan adiponektinaren maila igotzea eta inflamazio egoera nahiz intsulinarekiko erresistentzia jaistea lortu zen omega-3 gantz gehigarrien bidez [82]. Omega-3-en bidez gorputz-masa, tentsio arteriala eta kolesterol maila jaisten dira [83]. Gainera, omega-3 GAk aktibitate fisikoarekin konbinatzen zituzten umeek triglizerido eta intsulinarekiko erresistentzia ebaluatzeko probaren (HOMA) mailak aktibitate fisikoa egiten zutenek baino gehiago jaistea lortu zuten [84].

Helduetan egindako ikerketetan, gainpisua zeukaten pazienteek omega-3 gehigarrien bidez lortu zuten triglizerido maila jaistea, HDL kolesterol maila igotzea eta endotelioaren menpeko arterietako hodi-zabalkuntza hobetzea. Gainera, gehigarrien nahiz ariketa fisikoaren bidez, baina era independentean, gantz-masa jaistea lortu zen [85], hala gehigarri honen funtzionaltasuna agerian jarriz.

\section{ETORKIZUNERAKO IKUSPEGIA}

Berrikuspen honek kate luzeko omega-3 GA gehigarriak zenbait egoera klinikotan izan ditzakeen efektu mesedegarriak biltzen ditu. Batetik, oina- 
rrizko ikerkuntzan azken hamarkadetan bihotz-hodietako gaixotasunetan, minbizian, neuroendekapenezko gaixotasunetan, alkoholismoan eta gainpisuan omega-3 GA osagarriaren rola prebentzio neurri eta tratamendu gisa aztertu da; gehigarri horren onurak azpimarratuz. Bestetik, hainbat ikerketa klinikotan pazienteek omega-3 osagaia jasotzean izaten dituzten onurak eta egiaztatu diren aurrerapausoak biltzen ditu, frogatuz eta egiaztatuz bihotzhodietako gaixotasun, minbizi, neuroendekapenezko gaixotasun, alkoholismo eta gainpisu terapietan tratamendurako osagarri aproposa izan daitekeela (2. taula).

Omega-3 baliagarritasunaren inguruko interesa urtez urte eta ikerketaz ikerketa handituz joan da. Dietaren bitartez jasotzeak erosotasun handiko tratamendu ez-inbaditzailerako osagarri egokia bilakatzen du. Horrez gain, aipatu beharra dago gaur arte, eta farmakoetan ez bezala, ez dela deskribatutako albo ondoriorik ezagutzen.

Berrikusketa honetan zehaztasun handiz deskribatu diren hainbat egoera kliniko horietaz aparte, omega-3 GAk ere beste hainbat patologiaren tratamenduetan osagarri gisa erabili ohi dira. Omega-3 GAek esklerosi anizkoitzean, eskizofrenian [86, 87], garun lesio traumatikoan [88], autismoan, elikadura nahasmenduan, nahasmendu obsesibo-konpultsiboan eta depresioan $[89,90]$ zeresan handia daukate. Areago, arrain olio gehigarriaren bidez diabetesa pairatzen duten pazienteek injektatu beharreko intsulina kantitatea baxuagoa izatea lortu da [91]. Azken urteetan omega-3-en baliagarritasuna opioide menpekotasunaren aurkako tratamenduan osagarri gisa aztertzen ari da, eta orain arte emaitza itxaropentsuak lortu dira [92]. Horregatik guztiagatik omega-3 GAk, epe luzera, hainbat gaixotasuni aurrea hartzeko edo halakoak tratatzeko etorkizun handiko gehigarria bilakatzen ari dira; dietaren bidez har ditzakegun propietate osagarri eta sendagarriko mantenugaiak baitira, edonoren eskura daudenak. 
2. taula. Aztertutako gaixotasunek eragindako kalteen eta omega-3 gantz-azidoen onuren laburpen taula.

\begin{tabular}{|c|c|c|}
\hline Gaixotasuna & Gaixotasunaren ondorioak & Omega-3-en onurak \\
\hline $\begin{array}{l}\text { Bihotz-hodietako } \\
\text { gaixotasunak }\end{array}$ & $\begin{array}{l}\text { Bihotzeko arazoak } \\
\text { Ezkerreko bentrikuluko kalteak } \\
\text { Garun kalteak } \\
\text { Asaldurak gai zurian } \\
\text { Buruko isurien errepikapena } \\
\text { Arazo motorrak } \\
\text { Oroimen eta ikasketa arazoak } \\
\text { Ospitalizazioa } \\
\text { Heriotza }\end{array}$ & $\begin{array}{l}\text { Arritmiak, takikardiak eta fibrilazioak murriztu } \\
\text { Funtzio sistoliko eta bolumen gaitasuna hobetu }^{2} \\
\text { Kaltetutako garun azalera eta larritasuna jaitsi }{ }^{1} \\
\text { Angiogenesia eta neurogenesia areagotu } \\
\text { Errepikapenen murriztapena }^{2} \\
\text { Ezaugarri motorrak hobetu }^{1} \\
\text { Oroimen eta ikasketa arazoak hobetu } \\
\text { Ospitalizazio-maila gutxitu }^{1} \\
\text { Biziraupena handitu }^{2}\end{array}$ \\
\hline Minbizia & $\begin{array}{l}\text { Tumoreen hazkuntza } \\
\text { Metastasia } \\
\text { Pisu galera } \\
\text { Heriotza }\end{array}$ & $\begin{array}{l}\text { Zelula bideragarritasuna eta entzima onkogenikoen } \\
\quad \text { aktibitatea gutxitu }{ }^{1} \\
\text { Tumore oldarkortasuna }{ }^{1,2} \text { eta metastasi probabili- } \\
\quad \text { tatea jaitsi }{ }^{1} \\
\text { Pisua irabaztea bultzatu }{ }^{2} \\
\text { Errezidiba jaitsi; biziraupena handitu }{ }^{2}\end{array}$ \\
\hline $\begin{array}{c}\text { Endekapenezko } \\
\text { gaixotasunak }\end{array}$ & $\begin{array}{l}\text { Garun kalteak } \\
\text { Neuronen heriotza } \\
\text { Amiloide plaken pilaketa } \\
\text { Odoljarioak } \\
\text { Inflamazioa } \\
\text { Oroimen kaltetua }\end{array}$ & $\begin{array}{l}\text { Dendriten egoera hobetu; oxidazio-estresa jaitsi }{ }^{1} \\
\text { Neuronen proliferazioa bultzatu; heriotza ekidin }{ }^{1} \\
\text { Amiloide plaken sorkuntza eta pilaketa murriztu }^{1} \\
\text { Odoljarioak murriztu } \\
\text { Glia aktibazioa eta } \mathrm{TNF} \alpha \text {-ren adierazpena mu- } \\
\quad \mathrm{rriztu}^{1,2} \\
\text { Oroimen espaziala eta aldizkako oroimena hobe- } \\
\mathrm{tu}^{1,2}\end{array}$ \\
\hline Alkohola & $\begin{array}{l}\text { Garun kalteak } \\
\text { Arazoak portaera sozialean } \\
\text { Gibel kaltetua } \\
\text { Ar gonada kaltetuak }\end{array}$ & $\begin{array}{l}\text { Hipokanpoko plastikotasun sinaptikoa leheneratu; } \\
\quad \text { oxidazio-estresa jaitsi }^{1} \\
\text { Portaera soziala hobetu } \\
\text { Inflamazio zitokinen maila eta gantz pilaketa gu- } \\
\quad \text { txitu }^{1} \\
\text { Testosterona mailak leheneratu; espermatozoide } \\
\quad \text { kalitatea eta aldaketa histopatologikoak hobetu }^{1}\end{array}$ \\
\hline Gainpisua & $\begin{array}{l}\text { Inflamazioa } \\
\text { Glukosa eta GA metabolismo } \\
\text { kaltetua } \\
\text { Hipertriglizeridemia eta hiper- } \\
\quad \text { kolesterolemia } \\
\text { Intsulinarekiko erresistentzia } \\
\text { Hipertentsioa } \\
\text { Gaixotasun batzuk garatzeko } \\
\text { arrisku faktorea }\end{array}$ & $\begin{array}{l}\text { Inflamazio zitokinen maila jaitsi } i^{1,2} \\
\text { Adiponektina sorrera bultzatu }{ }^{1,2} \text {; arnas kateko kal- } \\
\quad \text { teak leheneratu }{ }^{1} \\
\text { Triglizerido eta kolesterol mailak jaitsi }{ }^{1,2} \\
\text { Intsulina eta glukosa mailak jaitsi }{ }^{1,2} \\
\text { Arterietako hodi-zabalkuntza hobetu }{ }^{2} \\
\text { PPAR } \gamma \text {-ren adierazpena eta abdomeneko gantz } \\
\quad \text { kantitatea jaitsi }^{1}\end{array}$ \\
\hline
\end{tabular}

${ }^{1}$ Oinarrizko ikerkuntzan frogatutako onurak.

${ }^{2}$ Ikerketa klinikoan frogatutako onurak. 
Maitane Serrano, Irantzu Rico-Barrio, Leire Lekunberri, Almudena Ramos-Uriarte, Nagore Puente, Izaskun Elezgarai, Pedro Grandes

\section{ESKER ONAK}

Hauen babes eta finantzazioari esker egin da lan hau: Eusko Jaurlaritza (IT1230-19); Red de Trastornos Adictivos, Instituto de Salud Carlos III (ISC-III) eta Europar Batasunaren Europako Eskualde Garapenerako Funtsa (ERDF-EU; RD16/0017/0012); MINECO/FEDER, UE (SAF201565034-R); Euskal Herriko Unibertsitateko doktoratu aurreko ikertzaileen kontratua (PIF 19/164) (MS) eta Euskal Herriko Unibertsitateko doktoratu aurreko ikertzaileen kontratua (PIF 18/315) (L.L).

\section{BIBLIOGRAFIA}

[1] Aguilera García, C., NAVARRo Alarcón, M., ALONSO APERTE, E., ÁLVAREZ MERCADO, AI., CARVAJALES, P.A. eta ARREDONDO OLGUÍN, MIGUEL. 2017. Tratado de nutrición. Tomo I. Bases fisiológicas y bioquímicas de la nutrición. Editorial Médica Panamericana, Madrid.

[2] JONES, P.J.H. eta RIDEOUT, TC. 2017. «Lipids, sterols and their metabolites». Modern Nutrition in Health Disease, 65-87.

[3] BADUI, S. 2006. Química de los alimentos. Pearson Educación, Mexico.

[4] BOWEN, K.J., HARRIS, W.S. eta KRIS-ETHERTON, P.M. 2016. «Omega-3 fatty acids and cardiovascular disease: Are there benefits?». Current Treatment Options in Cardiovascular Medicine, 18.

[5] GÓMEZ CANDELA, C., BERMEJO LÓPEZ, L.M. eta LORIA KOHEN, V. 2011. «Importance of a balanced omega6/omega 3 ratio for the maintenance of health. Nutritional recommendations». Nutrición Hospitalaria, 26, 323329.

[6] ABEDI, E. eta SAHARI, M.A. 2014. «Long-chain polyunsaturated fatty acid sources and evaluation of their nutritional and functional properties». Food Science and Nutrition, 2, 443-463.

[7] KAJARABILLE, N., FERNÁNDEZ-QUINTELA, A. eta PUY PORTILLO, M. 2018. «Omega-3 gantz-azidoak eta osasuna». Ekaia, 34.

[8] TRUMBO, P., SCHLICKER, S., YATES, A.A. eta POOS, M. 2005. Food and Nutrition Board of the Institute of Medicine, The National Academies. The National Academies Press, Washington.

[9] CALDER, P.C. 2016. «Docosahexaenoic acid». Annals of Nutrition and Metabolism, 69, 8-21.

[10] KAWAKITA, E., HASHIMOTO, M., SHIDO, O. 2006. «Docosahexaenoic acid promotes neurogenesis in vitro and in vivo». Neuroscience, 139, 991-997.

[11] BOUSQUET, M., SAINT-PIERRE, M., JULIEN, C., SALEM, N., CICCHETTI, F. eta CALON, F. 2008. «Beneficial effects of dietary omega-3 polyunsaturated fatty acid on toxin-induced neuronal degeneration in an animal model of Parkinson's disease». The FASEB Journal, 22, 1213-1225. 
[12] PINAZO-DURAN, M.D. eta BOSCÁ-GOMAR, L. 2012. «Anti-inflammatory properties of polyunsaturated fatty acid omega 3. Indications in ophthalmology». Archivos de la Sociedad Española de Oftalmología, 87, 203-205.

[13] SONI, N., ROSS, A.B., SCHEERS, N., NOOKAEW, I., GABRIELSSON, B.G. eta SANDBERG, A. 2019. «The omega-3 fatty acids EPA and DHA, as a part of a murine high-fat diet, reduced lipid accumulation in brown and white adipose tissues». International Journal of Molecular sciences, 20.

[14] ANDERSON, E.J., THAYNE, K.A., HARRIS, M., SHAIKH, S.R., DARDEN, T.M., LARK, D.S., WILLIAMS, J.M., CHITWOOD, W.R., KYPSON, A.P. eta RODRIGUEZ, E. 2014. «Do fish oil omega-3 fatty acids enhance antioxidant capacity and mitochondrial fatty acid oxidation in human atrial myocardium via PPAR $\gamma$ activation?». Antioxidants and Redox Signaling, 21, 1156-1163.

[15] MUNDUKO OSASUN ERAKUNDEA. Enfermedades cardiovasculares [online argitaraldia]. URL Eskuragarri: https://www.who.int/es/newsroom/fact-sheets/detail/cardiovascular-diseases-(cvds). 2017ko maiatzaren $17 \mathrm{a}$.

[16] AGENCIA EFE. Euskadi es una de las tres comunidades con menor mortalidad cardiovascular [online argitaraldia]. URL Eskuragarri: https://www. elmundo.es/pais-vasco/2016/04/19/571620ba22601d15528b46c2.html. 2016ko apirilaren 19a.

[17] PEPE, S. eta MCLENNAN, P.L. 1996. «Dietary Fish Oil Confers Direct Antiarrhythmic Properties on the Myocardium of Rats».The Journal of $\mathrm{Nu}$ trition, 126, 34-42.

[18] ABDUKEYUM, G.G., OWEN, A.J. eta MCLENNAN, P.L. 2008. «Dietary (n-3) long-chain polyunsaturated fatty acids inhibit ischemia and reperfusion arrhythmias and infarction in rat heart not enhanced by ischemic preconditioning». The Journal of Nutrition, 138, 1902-1909.

[19] ZEGHICHI-HAMRI, S., DE LORGERIL, M., SALEN, P., CHIBANE, M., DE LEIRIS, J., BOUCHER, F. eta LAPORTE, F. 2010. «Protective effect of dietary n-3 polyunsaturated fatty acids on myocardial resistance to ischemiareperfusion injury in rats». Nutrition Research, 30, 849-857.

[20] CAI, M., ZHANG, W., WENG, Z., STETLER, R.A., JIANG, X., SHI, Y., GAO, Y. eta CHEN, J. 2017. «Promoting neurovascular recovery in aged mice after ischemic stroke - prophylactic effect of Omega-3 polyunsaturated fatty acids». Aging and Disease, 8, 531-545.

[21] GONZALO-GOBERNADO, R., AYUSO, M.I., SANSONE, L., BERNALJIMÉNEZ, J.J., RAMOS-HERRERO, V.D., SÁNCHEZ-GARCÍA, E., RAMOS, T.L., ABIA, R., MURIANA, F.J.G., BERMÚDEZ, B., eta MONTANER, J. 2019. «Neuroprotective effects of diets containing olive oil and DHA/EPA in a mouse model of cerebral ischemia». Nutrients, 11.

[22] NAKAZAKI, E., YABUKI, Y., IZUMI, H., SHINODA, Y., WATANABE, F., HISHIDA, Y., KAMIMURA, A. eta FUKUNAGA, K. 2019. «Combined citicoline and docosahexaenoic acid treatment improves cognitive dys- 
Maitane Serrano, Irantzu Rico-Barrio, Leire Lekunberri, Almudena Ramos-Uriarte, Nagore Puente, Izaskun Elezgarai, Pedro Grandes

function following transient brain ischemia». Journal of Pharmacological Sciences, 139, 319-324.

[23] PU, H., JIANG, X., HU, X., XIA, J., HONG, D., ZHANG, W., GAO, Y., CHEN, J. eta SHI, Y. 2016. «Delayed docosahexaenoic acid treatment combined with dietary supplementation of omega-3 fatty acids promotes longterm neurovascular restoration after ischemic stroke». Translational Stroke Research, 7, 521-534.

[24] MARCHIOLI, R. 2001. «Treatment with n-3 polyunsaturated fatty acids after myocardial infarction: Results of GISSI-Prevenzione Trial». European Heart Journal Supplements, 3, 85-97.

[25] TAVAZZI, L., TOGNONI, G., FRANZOSI, M.G., LATINI, R., MAGGIONI, A.P., MARCHIOLI, R., NICOLOSI, G.L. eta PORCU, M. 2004. «Rationale and design of the GISSI heart failure trial: A large trial to assess the effects of n-3 polyunsaturated fatty acids and rosuvastatin in symptomatic congestive heart failure». European Journal of Heart Failure, 6, 635641.

[26] TANAKA, K., ISHIKAWA, Y., YOKOYAMA, M., ORIGASA, H., MATSUZAKI, M., SAITO, Y., MATSUZAWA, Y., SASAKI, J., OIKAWA, S., HISHIDA, H., ITAKURA, H., KITA, T., KITABATAKE, A., NAKAYA, N., SAKATA, T., SHIMADA, K. eta SHIRATO K. 2008. «Reduction in the recurrence of stroke by eicosapentaenoic acid for hypercholesterolemic patients: Subanalysis of the JELIS trial». Stroke, 39, 2052-2058.

[27] NODARI, S., TRIGGIANI, M., CAMPIA, U., MANERBA, A., MILESI, G., CESANA, B.M., GHEORGHIDAE, M. eta DEI CAS, L. 2011. «Effects of n-3 polyunsaturated fatty acids on left ventricular function and functional capacity in patients with dilated cardiomyopathy». Journal of the American College of Cardiology, 57, 870-879.

[28] ABDELHAMID, A.S., BROWN, T.J., BRAINARD, J.S., BISWAS, P., THORPE, G.C., MOORE, H.J., DEANE, K.H.O., ALABDULGHAFOOR, F.K., SUMMERBELL, C.D., WORTHINGTON, H.V., SONG, F. eta HOOPER, L. 2018. «Omega-3 fatty acids for the primary and secondary prevention of cardiovascular disease». The Cochrane database of systematic reviews, 18.

[29] MUNDUKO OSASUN ERAKUNDEA. Cancer [online argitaraldia]. URL Eskuragarri: https://www.who.int/health-topics/cancer\#tab=tab_1. 2018.

[30] ASOCIACIÓN ESPAÑOLA CONTRA EL CÁNCER. Observatorio AECC [online argitaraldia]. URL Eskuragarri: http://observatorio.aecc.es/. 2020.

[31] KUBAN-JANKOWSKA, A., GORSKA-PONIKOWSKA, M., SAHU, K.K., KOSTRZEWA, T., WOZNIAK, M. eta TUSZYNSKI, J. 2019. «Docosahexaenoic acid inhibits PTP1B phosphatase and the viability of MCF-7 breast cancer cells». Nutrients, 11.

[32] PIZATO, N., KIFFER, L.F.M.V., LUZETE, B.C., ASSUMPÇÃO, J.A.F., CORREA, L.H., DE MELO, H.A.B., DE SANT'ANA, L.P., ITO, M.K. eta 
MAGALHÃES, K.G. 2019. «Omega 3-DHA and delta-tocotrienol modulate lipid droplet biogenesis and lipophagy in breast cancer cells: The impact in cancer aggressiveness». Nutrients, 11.

[33] ZHU, S., FENG, N., LIN, G., TONG, Y., JIANG, X., YANG, Q., WANG, S., CHEN, W., HE, Z. eta CHEN, Y.Q. 2018. «Metabolic Shift Induced by $\omega-3$ PUFAs and Rapamycin Lead to Cancer Cell Death». Cellular Physiology and Biochemistry, 48, 2318-2336.

[34] Rose, D.P., Connolly, J.M. eta COLEMAN, M. 1996. «Effect of omega 3 fatty acids on the progression of metastases after the surgical excision of human breast cancer cell solid tumors growing in nude mice». Clinical Cancer Research, 2, 1751-1756.

[35] BRATTON, B.A., MALY, I.V. eta HOFMANN, W.A. 2019. «Effect of polyunsaturated fatty acids on proliferation and survival of prostate cancer cells». PLoS One, 14.

[36] McEntee, M.F., Ziegler, C., Reel, D., Tomer, K., Shoieb, A., Ray, M., Li, X., Neilsen, N., Lih, F.B., O`Rourke, D. eta WHELAN, J. 2008. «Dietary n-3 polyunsaturated fatty acids enhance hormone ablation therapy in androgen-dependent prostate cancer». American Journal of Pathology, 173, 229241.

[37] WANG, S., WU, J., SUBURU, J., GU, Z., CAI, J., AXANOVA, L.S., CRAMER, S.D., THOMAS, M.J., PERRY, D.L., EDWARDS, I.J., MUCCI, L.A., SINNOTT, J.A., LODA, M.F., SUI, G., BERQUIN, I.M. eta CHEN, Y.Q. 2012. «Effect of dietary polyunsaturated fatty acids on castration-resistant Pten-null prostate cancer». Carcinogenesis, 33, 404-412.

[38] DARWITO, D., DHARMANA, E., RIWANTO, I., BUDIJITNO, S., SUWARDJO, S., PURNOMO, J., WIDODO, I., GHOZALI, A., ARYANDONO, T. eta ANWAR, S.L. 2019. «Effects of omega-3 supplementation on Ki-67 and VEGF expression levels and clinical outcomes of locally advanced breast cancer patients treated with neoadjuvant CAF chemotherapy: A randomized controlled trial report». Asian Pacific Journal of Cancer Prevention, 20, 911-916.

[39] MOLFINO, A., AMABILE, M.I., LiONETTO, L., SPAGNOLI, A., RAMACCINI, C., DE LUCA, A., SIMMACO, M., MONTI, M. eta MUSCARITOLI, M. 2019. «DHA oral supplementation modulates serum epoxydocosapentaenoic acid (EDP) levels in breast cancer patients». Oxidative Medicine and Cellular Longevity, 2019.

[40] SONG, M., ZHANG, X., MEYERHARDT, J.A., GIOVANNUCCI, E.L., OGINO, S., FUCHS, C.S. eta CHAN, A.T. 2017. «Marine omega-3 polyunsaturated fatty acid intake and survival after colorectal cancer diagnosis». Gut, 66, 1790-1796.

[41] VAN BLARIGAN, E.L., FUCHS, C.S., NIEDZWIECKI, D., YE, X., ZHANG, S., SONG, M., SALTZ, L.B., MAYER, R.J., MOWAT, R.B., WHITTOM, R., HANTEL, A., BENSON, A., ATIENZA, D., MESSINO, M., KINDLER, H., VENOOK, A., OGINO, S., GIOVANNUCCI, E.L. eta 
Maitane Serrano, Irantzu Rico-Barrio, Leire Lekunberri, Almudena Ramos-Uriarte, Nagore Puente, Izaskun Elezgarai, Pedro Grandes

MEYERHARDT, J.A. 2018. «Marine $\omega$-3 polyunsaturated fatty acid and fish intake after colon cancer diagnosis and survival: CALGB 89803 (Alliance)». Cancer Epidemiology, Biomarkers and Prevention, 27, 438-445.

[42] ASOCIACIÓN ESPAÑOLA CONTRA EL CÁNCER. ¿Qué es el cáncer? [online argitaraldia]. URL Eskuragarri: https://www.aecc.es/es/todosobre-cancer/que-es-cancer. 2018

[43] RYAN, A.M., REYNOLDS, J.V., HEALY, L., BYRNE, M., MOORE, J., BRANNELLY, N., MCHUGH, A., MCCORMACK, D. eta FLOOD, P. 2009. «Enteral nutrition enriched with eicosapentaenoic acid (EPA) preserves lean body mass following esophageal cancer surgery: Results of a double-blinded randomized controlled trial». Annals of Surgery, 249, 355-363.

[44] VAN DER MEIJ, B.S., LANGIUS, J.A.E., SMIT, E.F., SPREEUWENBERG, M.D., VON BLOMBERG, B.M.E., HEIJBOER, A.C., PAUL, M.A. eta VAN LEEUWEN, P.A.M. 2010. «Oral nutritional supplements containing (n-3) polyunsaturated fatty acids affect the nutritional status of patients with atage III non-small cell lung cancer during multimodality treatment». The Journal of Nutrition, 140, 1774-1780.

[45] WERNER, K., KÜLLENBERG DE GAUDRY, D., TAYLOR, L.A., KECK, T., UNGER, C., HOPT, U.T. eta MASSING, U. 2017. «Dietary supplementation with n-3-fatty acids in patients with pancreatic cancer and cachexia: marine phospholipids versus fish oil - a randomized controlled double-blind trial». Lipids in Health and Disease, 16, 1-12.

[46] BARBER, M.D., ROSS, J.A., VOSS, A.C., TISDALE, M.J. eta FEARON, K.C.H. 1999. «The effect of an oral nutritional supplement enriched with fish oil on weight-loss in patients with pancreatic cancer». British Journal of Cancer, 81, 80-86.

[47] JPND RESEARCH. ¿Qué es una enfermedad neurodegenerativa? [online argitaraldia]. URL Eskuragarri: https://www.neurodegenerationresearch.eu/es/ que-es-una-enfermedad-neurodegenerativa/. 2019.

[48] BIOCRUCES BIZKAIA. Biocruces Bizkaia participa en varias líneas de investigación de la enfermedad de Alzheimer y demencias en general [online argitaraldia]. URL Eskuragarri: https://www.biocrucesbizkaia.org/-/ biocruces-bizkaia-participa-en-varias-lineas-de-investigacion-sobre-de-laenfermedad-de-alzheimer-y-demencias-en-general-. 2018ko irailaren 20a.

[49] CALON, F., LIM, G.P., YANG, F., MORIHARA, T., TETER, B., UBEDA, O., ROSTAING, P., TRILLER, A., SALEM, N.J., ASHE, K.H., FRAUCHTSY, S. eta COLE, G.M. 2004. «Docosahexaenoic acid protects from dendritic patology in an alzheimer's disease mouse model». Neuron, 43, 633-645.

[50] LIM, G.P., CALON, F., MORIHARA, T., YANG, F., TETER, B., UBEDA, O., SALEM, N.J., FRAUTSCHY, S. eta COLE, G.M. 2005. «A diet enriched with the omega-3 fatty acid docosahexaenoic acid reduces amyloid burden in an aged Alzheimer mouse model». Journal of Neuroscience, 25, 3032-3040. 
[51] HUR, J., MATEO, V., AMALRIC, N., BABIAK, M., BÉRÉZIAT, G., KANONY-TRUC, C., CLERC, T., BLAISE, R. eta LIMON, I. 2018. «Cerebrovascular b-amyloid deposition and associated microhemorrhages in a Tg2576 Alzheimer mouse model are reduced with a DHA-enriched diet». The FASEB Journal, 32, 4972-4983.

[52] FIOL-DEROQUE, M.A., GUTIERREZ-LANZA, R., TERÉS, S., TORRES, M., BARCELÓ, P., RIAL, R.V., VERKHRATSKY, A., ESCRIBÁ, P.V., BUSQUETS, X. eta RODRÍGUEZ, J.J. 2013. «Cognitive recovery and restoration of cell proliferation in the dentate gyrus in the 5XFAD transgenic mice model of Alzheimer's disease following 2-hydroxy-DHA treatment». Biogerontology, 14, 763-775.

[53] MORI, M.A., DELATTRE, A.M., CARABELli, B., PUDELL, C., BORTOLANZA, M., STAZIAKI, P.V., VISENTAINER, J.V., FERNANDES MONTANHER, P., DEL BEL, E.A. eta CURTE FERRAZ, A. 2018. «Neuroprotective effect of omega-3 polyunsaturated fatty acids in the 6-OHDA model of Parkinson's disease is mediated by a reduction of inducible nitric oxide synthase». Nutritional Neuroscience, 21, 341-351.

[54] GÓMEZ-SOLER, M., CORDOBILLA, B., MORATÓ, X., FERNÁNDEZDUEÑAS, V., DOMINGO, J.C., eta CIRUELA, F. 2018. «Triglyceride form of docosahexaenoic acid mediates neuroprotection in experimental parkinsonism». Frontiers in Neuroscience, 12.

[55] Eriksdotter, M., Vedin, I., Falahati, F., Freund-Levi, Y., Hjorth, E., FaxenIrving, G., Wahlund, L.O., Schultzberg, M., Basun, H., Cederholm, T. eta PALMBLAD, J. 2015. «Plasma fatty acid profiles in relation to cognition and gender in Alzheimer's disease patients during oral omega-3 fatty acid supplementation: The OmegAD Study». Journal of Alzheimer's Disease, 48, 805-812.

[56] FREUND-LEVI, Y., ERIKSDOTTER-JÖNHAGEN, M., CEDERHOLM, T., BASUN, H., FAXÉN-IRVING, G., GARLIND, A., VEDIN, I., VESSBY, B., WAHLUND, L.O. eta PALMBLAD, J. 2006. « $\omega-3$ fatty acid treatment in 174 patients with mild to moderate Alzheimer disease: OmegAD study- a randomized double-blind trial-». Archives of Neurology, 63, 1402-1408.

[57] RITCHIRE, C., BAJWA, J., COLEMAN, G., HOPE, K., JONES, R., LAWTON, M., MARVEN, M., eta PASSMOORE, P. 2014. «Souvenaid: A new approach to management of early Alzheimer's disease». The Journal of Nutrition, Health \& Aging, 18, 291-299.

[58] FREUND-LEVI, Y., BASUN, H., CEDERHOLM, T., FAXEN-IRVING, G., GARLIND, A., GRUT, M., VEDIN, I., PALBLAD, J., WAHLUND, L.O. eta ERIKSDOTTER, M. 2008. «Omega-3 supplementation in mild to moderate Alzheimer's disease: effects on neuropsychiatric symptoms». Clinical Interventions in Aging, 23, 261-169.

[59] TAGHIZADEH, M., TAMTAJI, O.R., DADGOSTAR, E., DANESHVAR KAKHAKI, R., BAHMANI, F., ABOLHASSANI, J., AARABI, M.H., KOUCHAKI, E., MEMARZADEH, M.R. eta ASEMI, Z. 2017. «The effects 
Maitane Serrano, Irantzu Rico-Barrio, Leire Lekunberri, Almudena Ramos-Uriarte, Nagore Puente, Izaskun Elezgarai, Pedro Grandes

of omega-3 fatty acids and vitamin E co-supplementation on clinical and metabolic status in patients with Parkinson's disease: A randomized, doubleblind, placebo-controlled trial». Neurochemistry International, 108, 183189.

[60] TAMTAJI, O.R., TAGHIZADEH, M., AGHADAVOD, E., MAFI, A., DADGOSTAR, E., DANESHVAR KAKHAKI, R., ALBOLHASSANI, J. eta ASEMI, Z. 2019. «The effects of omega-3 fatty acids and vitamin E cosupplementation on gene expression related to inflammation, insulin and lipid in patients with Parkinson's disease: A randomized, double-blind, placebo-controlled trial». Clinical Neurology and Neurosurgery, 176, 116-121.

[61] ATHAUDA, D. eta FOLTYNIE, T. 2016. «Insulin resistance and Parkinson's Disease: A new target for disease modification? ». Progress in neurobiology, 145-146, 98-120.

[62] MUNDUKO OSASUN ERAKUNDEA. Global status report on alcohol and health 2018. Munduko Osasun Erakundea, Geneva.

[63] EUSKO JAURLARITZAKO OSASUN SAILA. Encuesta sobre Adicciones de Euskadi [online argitaraldia]. URL Eskuragarri: https://www.euskadi.eus/ informacion/euskadi-y-drogas/web01-a3gabia/es/. 2020ko apirilaren 2a.

[64] MINISTERIO DE SANIDAD, POLÍTICA SOCIAL E IGUALDAD. ¿Sabías qué? [online argitaraldia]. URL Eskuragarri: https:/www.mscbs.gob.es/ campannas/campanas 11/alcoholenmenoresnoesnormal/sabias.html. 2011.

[65] SMITH, V.C. eta TURCHI, R. Trastornos del espectro alcohólico fetal: preguntas frecuentes de padres y familias [online argitaraldia]. URL Eskuragarri: https://www.healthychildren.org/Spanish/health-issues/conditions/ chronic/Paginas/Fetal-Alcohol-Spectrum-Disorders-FAQs-of-Parents-andFamilies aspx. 2019ko abuztuaren 20a.

[66] PATTEN, A.R., SICKMANN, H.M., DYER, R.A., INNIS, S.M. eta CHRISTIE, B.R. 2013. «Omega-3 fatty acids can reverse the long-term deficits in hippocampal synaptic plasticity caused by prenatal ethanol exposure». Neuroscience Letters, 551, 7-11.

[67] PATTEN, A.R., BROCARDO, P.S. eta CHRISTIE, B.R. 2013. «Omega-3 supplementation can restore glutathione levels and prevent oxidative damage caused by prenatal ethanol exposure». Journal of Nutritional Biochemistry, 24, 760-769.

[68] WELLMANN, K.A., GEORGE, F., BRNOUTI, F. eta MOONEY, S.M. 2015. «Docosahexaenoic acid partially ameliorates deficits in social behavior and ultrasonic vocalizations caused by prenatal ethanol exposure». Behavioural Brain Research, 286, 201-211.

[69] KAPOURCHALI, F.R., LOUIS, X.L., ESKIN, M.N.A. eta SUH, M. 2020. «A pilot study on the effect of early provision of dietary docosahexaenoic acid on testis development, functions, and sperm quality in rats exposed to prenatal ethanol». Birth Defects Research, 112, 93-104.

[70] UYGUR, R., YAGMURCA, M., ALKOC, O.A., GENC, A., SONGUR, A., UCOK, K. eta OZEN, O.A. 2014. «Effects of quercetin and fish n-3 fatty 
acids on testicular injury induced by ethanol in rats». Andrologia, 46, 356369.

[71] WANG, M., ZHANG, X., MA, L.J., FENG, R.B., YAN, C., SU, H., HE, C., KANG, J.X., LIU, B. eta WAN, J.B. 2017. «Omega-3 polyunsaturated fatty acids ameliorate ethanol-induced adipose hyperlipolysis: A mechanism for hepatoprotective effect against alcoholic liver disease». Biochimica et Biophysica Acta - Molecular Basis of Disease, 1863, 3190-3201.

[72] COLlinS, M.A., TAJUDDIN, N., MOON, K.H., KIM, H.Y., NIXON, K. eta NEAFSEY, E.J. 2014. «Alcohol, phospholipase A2-associated neuroinflammation and $\omega 3$ docosahexaenoic acid protection». Molecular Neurobiology, 50, 239-245.

[73] TAJUDDIN, N., MOON, K.H., MARSHALl, S.A., NIXON, K., NEAFSEY, E.J., KIM, H.Y. eta COLLINS, M.A. 2014. «Neuroinflammation and neurodegeneration in adult rat brain from binge ethanol exposure: Abrogation by docosahexaenoic acid». PLoS One, 9.

[74] MUNDUKO OSASUN ERAKUNDEA. Obesidad y soprebeso [online argitaraldia]. URL Eskuragarri: https:/www.who.int/es/news-room/fact-sheets/ detail/obesity-and-overweight. 2020ko apirilaren 1a.

[75] INSTITUTO NACIONAL DE ESTADÍSTICA. Encuesta Nacional de Salud [online argitaraldia]. URL Eskuragarri: https:/www.ine.es/dyngs/ INEbase/es/operacion.htm?c=Estadistica_C\&cid=1254736176783\&menu= resultados\&idp $=1254735573175 \#$ !tabs-1254736195650. 2018ko ekainaren $26 a$.

[76] DE MELLO, A.H., SCHRAIBER, R.B., GOLDIM, M.P.S., MATHIAS, K., MENDES, C., CORRÊA, M.E.A.B., GOMES, M.L., SILVEIRA, P.C.L., SCHUCK, P.F., PETRONILHO, F. eta TEZZA REZIN, G. 2019. «Omega-3 polyunsaturated fatty acids have beneficial effects on visceral fat in diet-induced obesity model». Biochemistry and Cell Biology, 97, 693-701.

[77] PÉREZ-MATUTE, P., PÉREZ-ECHARRI, N., MARTÍNEZ, J.A., MARTI, A. eta MORENO-ALIAGA, M.J. 2007. «Eicosapentaenoic acid actions on adiposity and insulin resistance in control and high-fat-fed rats: Role of apoptosis, adiponectin and tumour necrosis factor- $\alpha »$. British Journal of $\mathrm{Nu}$ trition, 97, 389-398.

[78] GONDIM, P.N., ROSA, P.V., OKAMURA, D., SILVA, V.D.O., ANDRADE, E.F., BIIHRER, D.A. eta PEREIRA, L.J. 2018. «Benefits of fish oil consumption over other sources of lipids on metabolic parameters in obese rats». Nutrients, $\mathbf{1 0}$.

[79] KALUPAHANA, N.S., CLAYCOMBE, K., NEWMAN, S.J., STEWART, T., SIRIWARDHANA, N., MATTHAN, N., LICHTENSTEIN, A.H. eta MOUSTAID-MOUSSA, N. 2010. «Eicosapentaenoic acid prevents and reverses insulin resistance in high-fat diet-induced obese mice via modulation of adipose tissue inflammation». The Journal of Nutrition, 140, 1915-1922.

[80] DE MELLO, A.H., SCHRAIBER, R.B., GOLDIM, M.P.S., GARCEZ, M.L., GOMES, M.L., DE BEM SILVEIRA, G., PEREIRA ZACCARON, 
Maitane Serrano, Irantzu Rico-Barrio, Leire Lekunberri, Almudena Ramos-Uriarte, Nagore Puente, Izaskun Elezgarai, Pedro Grandes

R., SCHUCK, P.F., BUDNI, J., SILVEIRA, P.C.L., PETRONILHO, F. eta TEZZA REZIN, G. 2019. «Omega-3 fatty acids attenuate brain alterations in high-fat diet-induced obesity model». Molecular Neurobiology, 56, 513-524.

[81] CHACIŃSKA, M., ZABIELSKI, P., KSIĄŻEK, M., SZAŁAJ, P., JARZĄBEK, K., KOJTA, I., CHABOWSKI, A. eta BLACHNIO-ZABIELSKA, A.U. 2019. «The impact of omega-3 fatty acids supplementation on insulin resistance and content of adipocytokines and biologically active lipids in adipose tissue of high-fat diet fed rats». Nutrients, 11.

[82] LÓPEZ-ALARCÓN, M., MARTÍNEZ-CORONADO, A., VELARDE-CASTRO, O., RENDÓN-MACÍAS, E. eta FERNÁNDEZ, J. 2011. «Supplementation of $n 3$ long-chain polyunsaturated fatty acid synergistically decreases insulin resistance with weight loss of obese prepubertal and pubertal children». Archives of Medical Research, 42, 502-508.

[83] GARCIA-CERVERA, E., FIGUEROA-VALVERDE, L., POOL GOMEZ, E., ROSAS-NEXTICAPA, M., LENIN, H.H., MATEU-ARMAND, V., PARRA-GALINDO, P eta CAUICH-CARRILLO, R. 2018. «Biological activity exerted by omega-3 fatty acids on body mass index, glucose, total cholesterol and blood pressure in obese children». Integrative Obesity and Diabetes, 4.

[84] HUANG, F., DEL-RÍO-NAVARRO, B.E., LEIJA-MARTINEZ, J., TORRES-ALCANTARA, S., RUIZ-BEDOLLA, E., HERNÁNDEZ-CADENA, L., BARRAZA-VILLARREAL, A., ROMERO-NAVA, R., SANCHÉZMUÑOZ, F., VILLAFAÑA, S., MARCHAT, L.A. eta HONG, E. 2019. «Effect of omega-3 fatty acids supplementation combined with lifestyle intervention on adipokines and biomarkers of endothelial dysfunction in obese adolescents with hypertriglyceridemia». Journal of Nutritional Biochemistry, 64, 162-169.

[85] HILL, A.M., BUCKLEY, J.D., MURPHY, K.J. eta HOWE, P.R.C. 2007. «Combining fish-oil supplements with regular aerobic exercise improves body composition and cardiovascular disease risk factors». American Journal of Clinical Nutrition, 85, 1267-1274.

[86] VALENZUELA, R., TAPIA, G., GONZÁLEZ, M. eta VALENZUELA, A. 2011. «Ácidos grasos omega-3 (EPA y DHA) y su aplicación en diversas situaciones clínicas». Revista Chilena de Nutrición, 38, 356-367.

[87] CALON, F. eta COLE, G. 2007. «Neuroprotective action of omega-3 polyunsaturated fatty acids against neurodegenerative diseases: Evidence from animal studies». Prostaglandins, Leukotrienes and Essential Fatty Acids, 77, 287-293.

[88] WU, A., YING, Z. eta GOMEZ-PINILLA, F. 2007. «Omega-3 fatty acids supplementation restores mechanism that maintain brain homeostasis in traumatic brain injury». Journal of Neurotrauma, 24, 1587-1595.

[89] HÄBERLING, I., BERGER, G., SCHMECK, K., HELD, U. eta WALITZA, S. 2019. «Omega-3 fatty acids as a treatment for pediatric depression. A 
phase III, 36 weeks, multi-center, double-blind, placebo-controlled randomized superiority study». Frontiers in Psychiatry, 10.

[90] PARLETTA, N., ZARNOWIECKI, D., CHO, J., WILSON, A., BOGOMOLOVA, S., VILLANI, A., ITSIOPOULOS, C., NIYONSENGA, T., BLINDEN, S., MEYER, B., SEGAL, L., BAUNE, B.T. eta O’DEA, K. 2019. «A Mediterranean-style dietary intervention supplemented with fish oil improves diet quality and mental health in people with depression: A randomized controlled trial (HELFIMED)». Nutritional Neuroscience, 22, 474-487.

[91] CADARIO, F., POZZI, E., RIZZOLLO, S., STRACUZZI, M., BEUX, S., GIORGIS, A., CARRERA, D., FULLIN, F., RISO, S., RIZZO, A.M., MONTORFANO, G., BAGNATI, M., DIANZANI, U., CAIMMI, P., BONA, G. eta RICORDI, C. 2019. «Vitamin D and $\omega-3$ supplementations in mediterranean diet during the 1 st year of overt type 1 diabetes: A cohort study». $\mathrm{Nu}$ trients, 11.

[92] HAKIMIAN, J.K., DONG, T.S., BARAHONA, J.A., LAGISHETTY, V., TIWARI. S., AZANI, D., BARRERA, M., LEE, S., SEVERINO, A.L., MITTAL, N., CAHIL, C.M., JACOBS, J.P. eta WALWYN, W.M. 2019. «Dietary supplementation with omega-3 polyunsaturated fatty acids reduces opioid-seeking behaviors and alters the gut microbiome». Nutrients, 11. 